\title{
Caracterização de patologias em marquises na cidade de Gurupi-To
}

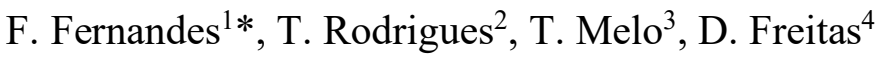 \\ *Autor Contato: fernandesfernando27@gmail.com \\ 1,2,3,4 Curso Engenharia Civil - UNIVERSIDADE UNIG, Gurupi -TO, Brasil, ${ }^{1,4}$ Curso \\ Engenharia Civil ITPAC PORTO NACIONAL, Porto Nacional -TO, Brasil
}

\section{RESUMO}

A frequência de acidentes com marquises no Brasil está ligada a falta de durabilidade. As manifestações patológicas identificadas nesta investigação foram realizadas na cidade de Gurupi/TO. As marquises investigadas foram selecionadas na região central da cidade de Gurupi/TO, após avaliação visual "In Loco", foram escolhidas as que que visualmente apresentavam patologias (mofo, bolor, trincas, desplacamento de revestimento). Os resultados podem servir para alertar sobre a importância e cuidado que se deve dar a este tipo de estrutura, porque apresentam ruptura brusca e colocam a vida das pessoas em risco, por geralmente estarem projetadas sobre passeios públicos. Os resultados mostram que $10 \%$ das marquises investigadas apresentam idade inferior a 10 anos, $40 \%$ entre 10 a 20 anos e $40 \%$ superior a 30 anos. As principais manifestações patológicas que incidem nas marquises são provocadas pelas infiltrações como mofo, bolor, trincas ocasionadas pela corrosão da armadura. A existência de impermeabilização foi verificada em $40 \%$ das marquises e $60 \%$ não apresentavam.

Palavra-chave: Impermeabilização; Água; Manutenção; Fissuras, Marquise.

\section{RESUMEN}


La frecuencia de accidentes con marquesinas en Brasil está vinculada a la falta de durabilidad. Las manifestaciones patológicas identificadas en esta investigación se llevaron a cabo en la ciudad de Gurupi / TO. Las marquesinas investigadas fueron seleccionadas en la región central de la ciudad de Gurupi / TO, luego de una evaluación visual "In Loco", se eligieron aquellas que presentaban patologías visualmente (moho, mildiu, grietas, descamación del recubrimiento). Los resultados pueden servir para alertar sobre la importancia y el cuidado que se debe dar a este tipo de estructuras, ya que presentan una ruptura repentina y ponen en riesgo la vida de las personas, ya que suelen proyectarse en las aceras públicas. Los resultados muestran que el 10\% de las marquesinas investigadas son menores de 10 años, el 40\% tienen entre 10 y 20 años y el $40 \%$ son mayores de 30 años. Las principales manifestaciones patológicas que afectan a las marquesinas son provocadas por infiltraciones como moho, mildiu, fisuras provocadas por la corrosión del refuerzo. Se verificó la existencia de impermeabilización en el $40 \%$ de los toldos y el $60 \%$ no la tenía.

Palabras clave: Impermeabilización; Agua; Mantenimiento; Grietas, marquesa.

\section{SUMMARY}

The frequency of accidents with marquees in Brazil is linked to the lack of durability. The pathological manifestations identified in this investigation were carried out in the city of Gurupi/TO. The investigated canopies were selected in the central region of the city of Gurupi/TO, after visual assessment "In Loco", those that visually presented pathologies were chosen (mold, mildew, cracks, peeling of the coating). The results can serve to alert about the importance and care that should be given to this type of structure, as they present a sudden rupture and put people's lives at risk, as they are usually projected on public sidewalks. The results show that $10 \%$ of the investigated canopies are younger than 10 years old, $40 \%$ are between 10 and 20 years old and $40 \%$ are older than 30 years old. The main pathological manifestations that affect the marquees are caused by infiltrations such as mold, mildew, cracks caused by corrosion of the reinforcement. The existence of waterproofing was verified in $40 \%$ of the awnings and $60 \%$ did not have it.

Keyword: Waterproofing; Water; Maintenance; Fissures, Marquise.

\section{INTRODUÇÃO}

A pandemia do COVID 19 que atingiu o mundo no ano de 2020, fez com que a população ficasse isolada em casa para evitar a contaminação e garantir o isolamento social. No Brasil vários setores adotaram o home office como forma de não parar suas atividades e preservar a saúde de seus trabalhadores.

De acordo com o levantamento do app "GetNinjas" entre os meses de abril a novembro de 2020, foram realizadas 2,8 milhões solicitações de serviços de reforma, uma alta de $75 \%$ em comparação com o mesmo período do ano 2019 (Lorran, 2020). O número específico de solicitações de reformas e reparos cresceu $57 \%$ nos últimos oito meses. Além disso, verificou-se que os serviços mais solicitados nessa área foram respectivamente, pedreiros e eletricistas (Lorran, 2020). 
A permanência por mais tempo em casa, fez com que os moradores começassem a observar as manifestações patológicas existentes em seus imóveis. Sabe-se que as residências, assim como outros tipos de imóveis necessitam de manutenção constante, a fim de preservar as próprias instalações e estrutura. Estes ambientes quando bem cuidados, tendem a ser valorizados e têm sua vida útil aumentada (SEBRAE, 2017).

Nos últimos anos no Brasil, tem se observado o crescimento na incidência de patologias em marquises de concreto de proteção, que na grande maioria dos casos são ocasionadas por falhas construtivas ou falta de projetos bem elaborados que podem contribuir para o enfraquecimento da estrutura pela penetração de água, podendo levá-la ao colapso gerando vítimas fatais (Novaes et al., 2021). Além das falhas, é possível observar que muitas estruturas não apresentam um comportamento satisfatório diante do propósito para que foram construídas. O conjunto de fatores involuntários, incluem tanto o desgaste natural em estruturas como acidentes e casos de imprudência, ao se utilizarem materiais inadequados por questões de economia, promovem a deterioração das estruturas. Nesse contexto, percebeu-se a necessidade da realização de estudos científicos sobre o comportamento das estruturas e os problemas que eram averiguados nelas, surgindo então a área de patologia no âmbito da engenharia civil (Weimer, 2018). O estudo das patologias em estruturas identifica as formas de manifestações e consequências, bem como, dos mecanismos responsáveis pela ocorrência dos defeitos em construções civis. Para se diagnosticar uma patologia e determinar os mecanismos de formação e sua gravidade é necessário identificar os sintomas através da observação e realização de estudos e ensaios específicos (Gasparett, Pantoja e Ramires, 2021). Em alguns casos, para se obter o diagnóstico correto, é necessário realizar ensaios minuciosos de laboratório, revisão de projetos e mesmo instrumentação e acompanhamento da obra (Gasparett, Pantoja e Ramires, 2021).

No setor da construção civil, é possível observar que desde os primórdios, as patologias estão presentes na maioria das obras de edificações, devido a diversos fatores. As manifestações patológicas têm origem por meio de problemas recorrentes durante sua vida útil, estando relacionadas ao tempo de vida da construção, ao clima, aos materiais e técnicas construtivas utilizadas e ao nível de controle de qualidade realizado (Carvalho, Oliveira e Monteiro, 2021; Porto e Pimenta, 2021). Entre as inúmeras manifestações patológicas existentes, as mais recorrentes são as trincas e fissuras (Porto e Pimenta, 2021). As fissuras podem ser classificadas dependendo se sofrem ou não movimentação, podendo ser classificadas como ativas ou passivas. Independente da classificação, é imperioso que seja escolhido o tratamento adequado para o caso, logo que é através das fissuras que a armadura que antes estava protegida pelo concreto, agora se encontra dando espaço para a penetração dos agentes agressores que despassivam a armadura e a deixam vulneráveis a corrosão (Carvalho, Oliveira e Monteiro, 2021). Estas patologias têm maior manifestação em estruturas de concreto armado.

As marquises de cobertura são elementos estruturais formados por laje e viga ou apenas a laje (Fabiane Sartori, 2013). No caso de marquises de proteção, a laje é engastada na viga, constituindo uma extremidade engastada e outra livre. Portanto a armadura principal, é negativa (momento negativo), podendo-se dispensar o uso de armadura de distribuição positiva. O surgimento de manifestações patológicas em marquises é o resultado de erros gerados na etapa de projeto, durante o processo construtivo, utilização, além de falhas no controle de qualidade (dos materiais e da execução) ou manutenção de uma ou mais atividades, tais como: corrosão das armaduras, escoramento mal executado, falta de manutenção da estrutura. $\mathrm{O}$ principal problema observado que reduz a vida útil das estruturas de concreto armado, e a corrosão de armaduras, sendo este mais 
frequente, também sendo responsável por grande parte dos danos nessas estruturas (Silvestro, Romano e Molin, 2021). Os danos podem ser observados quando começam a aparecer manchas superficiais, seguidas por fissuras, destacamento do concreto de cobrimento, redução da seção e perda de aderência das armaduras principais, podendo levar ao comprometimento da segurança estrutural ao longo do tempo. Os produtos originados pelo processo corrosivo são expansivos e resultam em aumento das tensões no interior do concreto, fazendo com que aconteça sua deterioração, o que contribui para a drástica redução da vida útil dessas estruturas (Gasparett, Pantoja e Ramires, 2021; Silvestro, Romano e Molin, 2021).

Objetivo deste trabalho foi identificar as manifestações patológicas com maior incidência em marquises de concreto na região central da cidade de Gurupi/TO como mofo, bolor, trincas, desplacamento de revestimento e pintura.

\section{DESENVOLVIMENTO}

Esta investigação avaliou de maneira visual 50 marquises em imóveis (residenciais/comerciais) que apresentavam manifestações patologias. O levantamento "In Loco" foi realizado na região central da cidade de Gurupi no estado do Tocantins. A região central da cidade foi escolhida porque apresentou maior concentração de marquises com manifestações de patologia e porque tem o maior fluxo de transeuntes. Entre as 50 marquises investigadas, teve um total de 11 que apresentaram (Mofo/ Bolor/ Trincas/Desplacamento Revestimento) e 22 (Mofo/ Bolor/ Trincas); sendo estas consideradas mais críticas. Destas, apenas 5 responderam ao questionário e permitiram o registro fotográfico; sem identificação do local. As outras não autorizaram nenhum tipo de registro; sendo excluídas desta investigação. $\mathrm{O}$ questionário aplicado foi elaborado com base na metodologia "Qualitativa", onde o foco concentrou-se no caráter subjetivo do objeto analisado para compreender o surgimento das manifestações patológicas e o conhecimento dos proprietários em relação a manutenção preventiva/corretiva. O questionário foi respondido pelo morador da edificação que reside a mais tempo para maior confiabilidade das respostas. Não foi feita a separação de marquises de edificações comerciais/residências, porque vários comércios também serviam de residências unifamiliar. As perguntas que fizeram parte do questionário que foi aplicado nesta investigação, são apresentadas na Tabela 1 .

Tabela 1. Relação de perguntas do questionário.

\begin{tabular}{ll}
\hline Item & Descrição \\
\hline 1 & Total de pavimentos existentes. \\
2 & A construção teve projeto. \\
3 & Idade da construção (anos).
\end{tabular}


4 Existiu escavações ou vibrações excessivas próximo.

5 Tipos de manifestações.

$6 \quad$ Nível de gravidade da patologia.

7 Existe impermeabilização.

8 Foi realizado manutenção (preventiva/corretiva).

\section{RESULTADOS}

Toda estrutura é dimensionada de modo a atender a duas situações: coeficientes apropriados de segurança relacionados ao colapso e comportamento satisfatório sob ação de cargas de serviço. Estas situações estão relacionadas aos estados limites últimos (ELU) e aos estados limites de serviço (ELS), respectivamente. Usa-se os estados limites para verificar o comportamento e a conformidade da estrutura para o seu uso, tornando-a inadequada quando eles são atingidos (Weimer, 2018). Segundo NBR 6118:2014, os estados limites têm relação com as seguintes condições: Estados limites últimos (ELU): relacionados ao máximo da capacidade portante da estrutura, determinando a paralisação do uso da edificação. O ELU é caracterizado basicamente por perda de equilíbrio da estrutura (risco de tombamento, escorregamento) e deformações excessivas dos materiais (causando instabilidade ou ruptura). Estados limites de serviço (ELS): relacionados com as condições de utilização normal da estrutura e com a sua durabilidade. O ELS é caracterizado basicamente pela abertura de fissuras, por deformações e vibrações excessivas. A Figura 1., apresenta o resultado das manifestações patologias encontradas em 50 marquises estruturais identificadas durante o levantamento para realização deste estudo na região central da cidade de Gurupi/TO. Os resultados ilustrados na figura mostram que 34\% das marquises apresentam patologias (pintura, mofo, bolor) que influenciam apenas na aparência do imóvel, 22\% (mofo, bolor, trincas) e 22\% (mofo, bolor, trincas, desplacamento de revestimento). Estes resultados mostram que a falta de manutenção corretiva e preventiva, poderia resolver grandes parte destas patologias, evitando que estas patologias se transformem em ocorrências mais prejudiciais as estruturas, podendo levar até ao colapso da estrutura.

Foi possível observar neste estudo que a grande maioria das edificações, tem a finalidade de locação para comercio. De acordo com os proprietários, isso não permite investimento em manutenção corretivas/preventivas. O que também foi observado é que grande parte dos imóveis 
estavam desocupados com aparência de abandono, esta situação pode ter sido influenciada pelo momento em que a cidade vive em decorrência da pandemia da COVID 19.

\section{PATOLOGIAS IDENTIFICADAS}

$\square$ Mofo/ Bolor/ Trincas/Desplacamento Revestimento $\square$ Mofo/ Bolor/ Trincas $\square$ Pintura $\square$ Mofo $\square$ Bolor

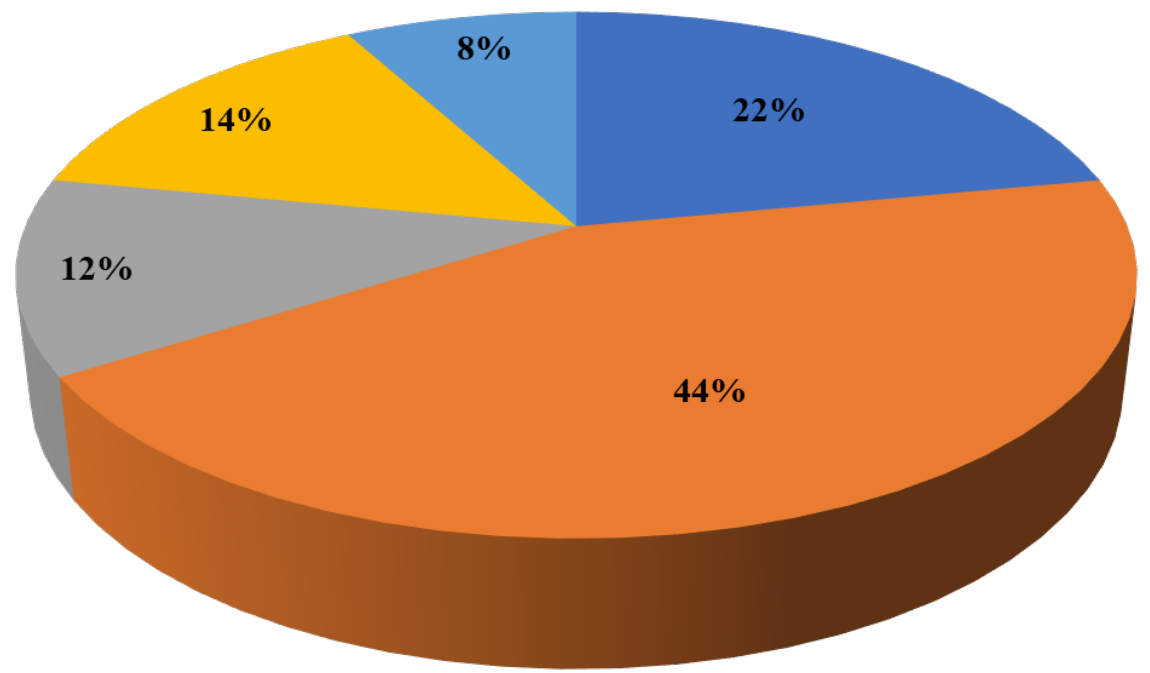

Figura 1. Patologias encontradas nas marquises durante a fase de levantamento.

\subsection{Questionamentos}

A Tabela 2. Apresenta a tabulação dos resultados das perguntas contidas no questionário, aplicado em 5 (cinco) imóveis que aceitaram e autorizaram a divulgação sem a identificação do local. A Figura 2. Apresenta o registro fotográfico das manifestações patológicas investigadas neste estudo.

Tabela 2. Relação das perguntas questionário aplicado. 


\begin{tabular}{|c|c|c|c|c|c|}
\hline \multirow{2}{*}{ Código } & \multicolumn{5}{|c|}{ Código da marquise } \\
\hline & $\mathbf{A}$ & B & C & D & $\mathbf{E}$ \\
\hline Total de pavimentos existentes & 2 & 3 & 1 & 1 & 1 \\
\hline A construção teve projeto? & não & não & não & $\operatorname{sim}$ & $\operatorname{sim}$ \\
\hline Idade da construção (anos)? & 32 & 18 & 16 & 7 & 36 \\
\hline $\begin{array}{l}\text { Existiu escavações ou vibrações } \\
\text { excessivas próximo. }\end{array}$ & não & não & não & não & não \\
\hline Tipos de manifestações & $\begin{array}{c}\text { mofo/ bolor/ } \\
\text { trincas/desplacam } \\
\text { ento }\end{array}$ & $\begin{array}{c}\text { mofo/ bolor/ } \\
\text { trincas/desplac } \\
\text { amento }\end{array}$ & $\begin{array}{l}\text { mofo/ } \\
\text { bolor/ } \\
\text { trincas }\end{array}$ & $\begin{array}{l}\text { mofo/ bolor/ } \\
\text { trin cas/despla } \\
\text { camento }\end{array}$ & $\begin{array}{l}\text { mofo/ } \\
\text { bolor/ } \\
\text { trincas }\end{array}$ \\
\hline Nível de gravidade da patologia. & médio & médio & baixo & baixo & médio \\
\hline Existe imperm eabilização & não & não & $\operatorname{sim}$ & não & $\operatorname{sim}$ \\
\hline $\begin{array}{l}\text { Foi realizado manutenção } \\
\text { (preventiva/corretiva) }\end{array}$ & $\operatorname{sim}$ & não & $\operatorname{sim}$ & não & $\operatorname{sim}$ \\
\hline
\end{tabular}



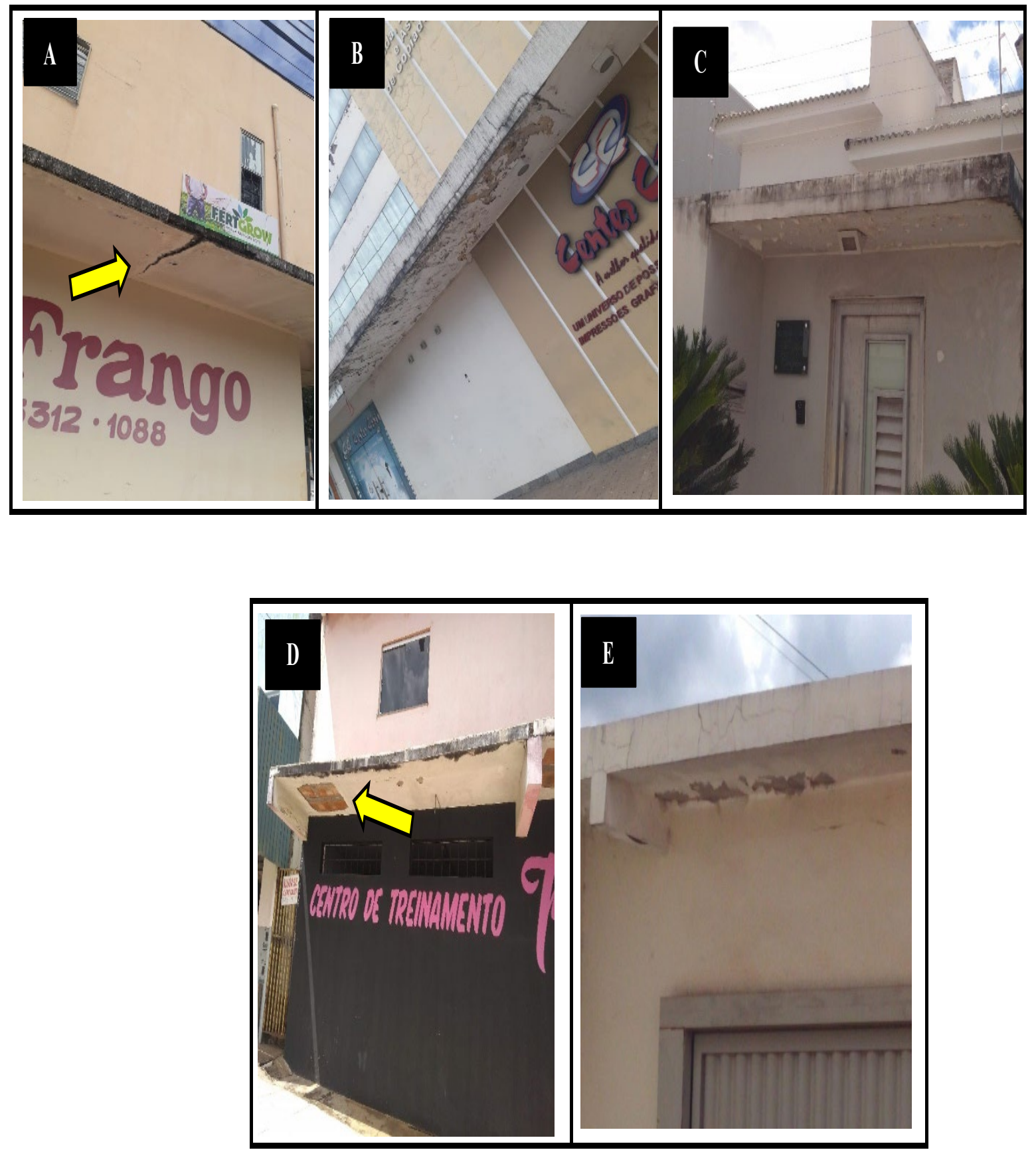

Figura 2. Registro fotográfico das marquises investigadas que responderam ao questionário.

Os registros fotográficos apresentados na Figura 2., foram realizados durante a fase de levantamento e identificação das patologias nas marquises, nas ruas do centro da cidade de Gurupi. Foram considerados nesta pesquisa, apenas as marquises com maior evolução patológica, para facilitar a explicação e o exemplo de cada tipo de patologia existente. 
Observando a Figura 2a, verificou-se a existência de uma fissura transversal que cruza a marquise na diagonal. Nesta investigação, não foi possível identificar se é uma fissura ativa ou passiva (Carvalho, Oliveira e Monteiro, 2021). De acordo com o proprietário a fissura já existia a bastante tempo e continua com mesma aparência. Para diagnosticar uma patologia e determinar as causas dos mecanismos de formação e da gravidade potencial de uma manifestação patológica, com base na observação dos sintomas, poderia nos induzir a erros. Para evitar estes erros é necessário a realização de estudos mais minuciosos (Carvalho, Oliveira e Monteiro, 2021). O surgimento desta fissura pode ter sido favorecido pelo tempo de vida útil da estrutura ter 32 anos, pela falta de impermeabilização na face superior e pela falta de manutenção corretiva ou preventiva. A falta de impermeabilização ou proteção adequada na marquise figura $2 \mathrm{a}$, pode ter contribuído para penetração da água da chuva que fica acumulada na marquise promovendo à corrosão da armadura (Carvalho, Oliveira e Monteiro, 2021), fazendo com que o aço se expandisse contribuindo para o aumento da fissura. A afirmação de acúmulo de água da chuva na face superior, foi confirmada pelo proprietário durante aplicação do questionário sendo reforçada pelo surgimento em toda a sua extensão de mofo e bolor, conforme ilustrado na Figura 2b (Carvalho, Oliveira e Monteiro, 2021). As marquises ilustradas na Figura 2b, d, com 18 e 7 anos, respectivamente, apresentam patologias bem similares em toda a sua extensão sendo possível verificar o surgimento de microfissuras, bolor e desplacamento de pequenas áreas de reboco (Fabiane Sartori, 2013). Observando as Figuras 2a, b, c, d é possível verificar que a pintura das peças estruturais encontra-se parcial ou totalmente comprometida. Na Figura 2a observa-se a existência de desplacamento de uma pequena parte de reboco. A fissura presente na face lateral da marquise Figura $2 \mathrm{~b}$, podem ter sido originadas pela água da chuva em excesso que vaza pela fissura. Esta água também pode favorecer a oxidação e posteriormente a corrosão do aço promovendo abertura desta fissura (Andrade, 2006). De acordo com o proprietário do imóvel, esta situação já tem bastante tempo e nunca teve o desplacamento de revestimento. O proprietário também comentou que nunca fez nenhuma manutenção, apenas mandou retirar $\left(1 \mathrm{~m}^{2}\right)$ de reboco que poderia cair, como ilustrado na figura. As marquises Figuras $2 \mathrm{~b}$, d durante a sua construção foram apenas rebocadas (argamassa) em todas as faces e depois receberam uma de mão de emulsão asfáltica na face superior. As marquises Figura 2c, d com $16 \mathrm{e}$ 36 anos respectivamente construídas apresentaram manifestações patológica na pintura, sendo resultado da formação de bolhas. De acordo com seus proprietários estas marquises receberam manutenção ( \pm 4 anos), onde apenas a marquise Figura $2 c$, recebeu aplicação de manta asfáltica em toda área da face superior e a marquise Figura 2e, apenas foi tratada com uma pintura de emulsão asfáltica em cima do reboco na face superior. De acordo com relato dos proprietários, os imóveis têm a finalidade somente de locação com isso não podem gastar muito com reformas preventivas ou corretivas. Também foi observado nesta marquise a falta de caimento da água da chuva para evitar o acúmulo de água na face superior. Como as marquises foram reformadas recentemente, não foi encontrado o surgimento de fissuras em nem uma estrutura.

\subsection{Representação dos resultados}

As perguntas e respostas do questionário aplicado aos moradores mais antigo das edificações onde foi possível investigar as manifestações patológicas nas marquises estruturais, são apresentados nas figuras abaixo. Na Figura 3., é apresentado o tempo da construção da estrutura. 


\section{TEMPO DE CONSTRUÇÃO (ANOS)}

\section{口Até 10 Entre 10 e 20 a Maior 30}

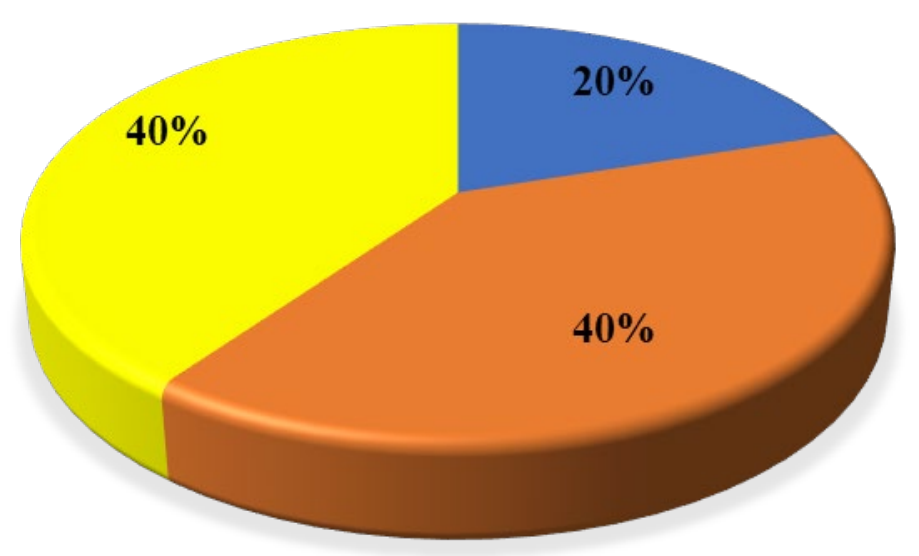

Figura 3. Tempo de construção em anos das estruturas investigadas.

Os resultados apresentados na Figura 3., mostram que o maior percentual de marquises investigadas apresenta idades superiores a 30 anos (40\%), seguida por marquises entre 10 e 20 anos (20\%). Estes resultados mostram que grande parte das peças estruturais investigadas neste estudo, foi construída em uma época que não existiam muitas soluções construtivas de fácil acesso como existe hoje, garantido a qualidade e a eficiência estrutural destas peças. Nesta época não existia muita precisão nos diagnósticos por causa da falta de uma investigação mais minuciosos e por ensaios de laboratórios mais precisos que pode-se identificar a origem e evolução das patologias como ensaio absorção capilar, traço/composição, porosidade e agentes agressivos, assim como profissionais com experiências para orientar (Gasparett, Pantoja e Ramires, 2021). A durabilidade de uma obra consiste na capacidade de a estrutura resistir às influências ambientais previstas e definidas em conjunto pelo autor do projeto estrutural e pelo contratante, no início da elaboração do projeto (Gasparett, Pantoja e Ramires, 2021). A idade da construção, ou tempo em que a construção existe, favorecem ao surgimento de patologias (Fabiane Sartori, 2013). A Figura 4, apresenta os tipos de patologistas que foram identificadas nas estruturas investigadas. 


\section{TIPO MANIFESTAÇÕES}

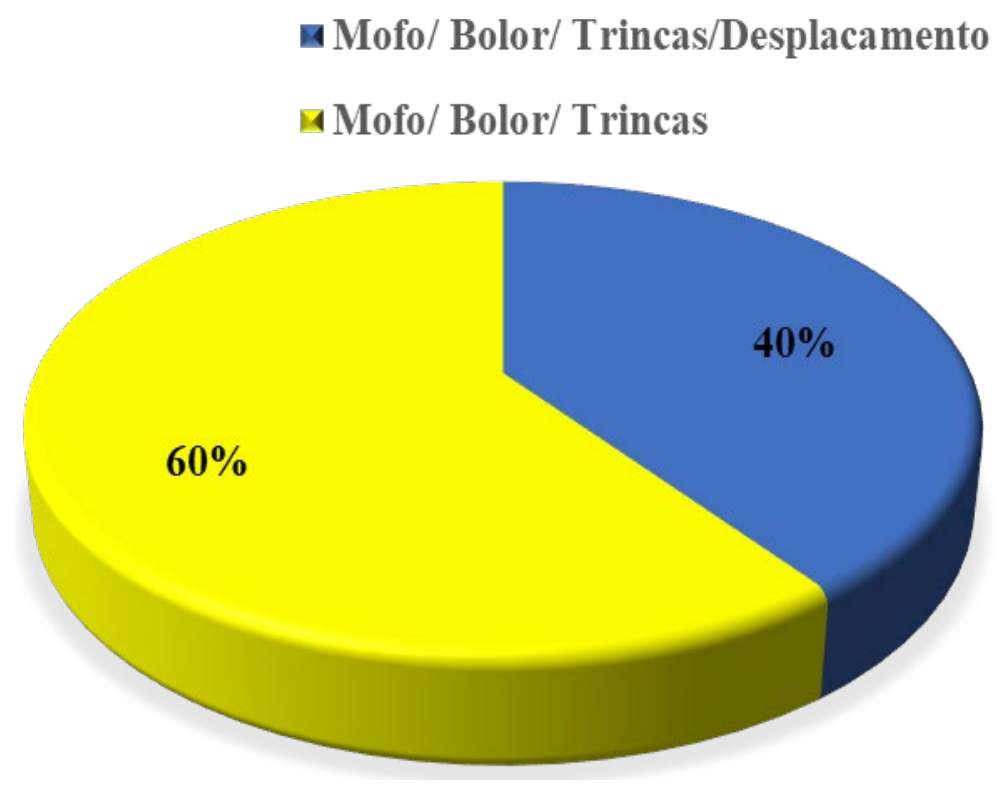

Figura 4. Tipo de manifestações nas estruturas investigadas.

Observando a Figura 4, 5 e 6., verificou-se que existe coerência entre os resultados apresentados nestas figuras. Isso porque, $60 \%$ das patologias apresentadas pelas marquises investigadas é caracterizada por: mofo, bolor e trincas (Silvestro, Romano e Molin, 2021), resultando em nível de gravidade baixo e $40 \%$ apresentam risco médio. Estes valores são similares aos resultados apresentados pela Figura 6., onde a falta de impermeabilização nas marquises chegou a 60\% e apenas $40 \%$ apresentaram. Este resultado também indica que o nível de gravidade apresentado pelas estruturas investigadas é influenciado pelo tipo de patologia ao qual a peça estrutural está submetida. Quando se observa a Figura 5., é possível verificar que a falta de impermeabilização tem forte influência no nível de gravidade da patologia e no tipo de manifestação patologia na estrutura, isso porque a penetração de água na estrutura fica mais fácil favorecendo o surgimento de manifestações patológicas. O risco médio Figura 5., é verificado pelo desplacamento de revestimento Figura 2b, c em valores mínimos de área. Este resultado é importante porque mostra que os revestimentos executados durante a execução das estruturas, apresenta boa aderência e resistência ao tempo, ocasionado possivelmente pela qualidade dos materiais e da mão-de-obra durante a construção da peça estrutural. Isso corrobora para garantir a segurança dos transeuntes nas calcadas onde existe este tipo de estrutura. A Figura 5, apesenta o nível de gravidade das patologias nas estruturas investigadas neste estudo. 


\section{NÍVEL DE GRAVIDADE DA PATOLOGIA}

a Baixo $₫$ Médio

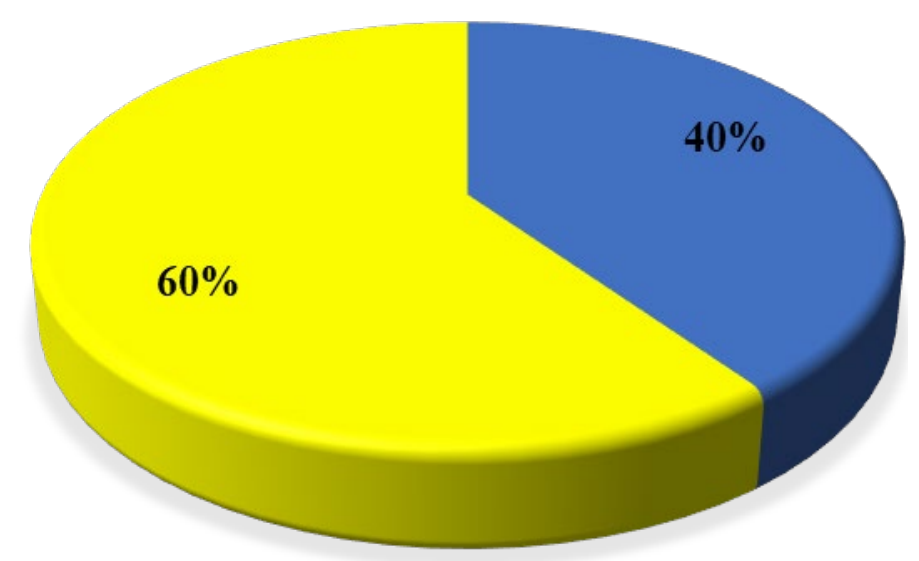

Figura 5. Nível de gravidade apresentado pelas estruturas investigadas.

\section{EXISTÊNCIA DE IMPERMEABILIZAÇÃO \\ ロ Sim $\square$ Não}

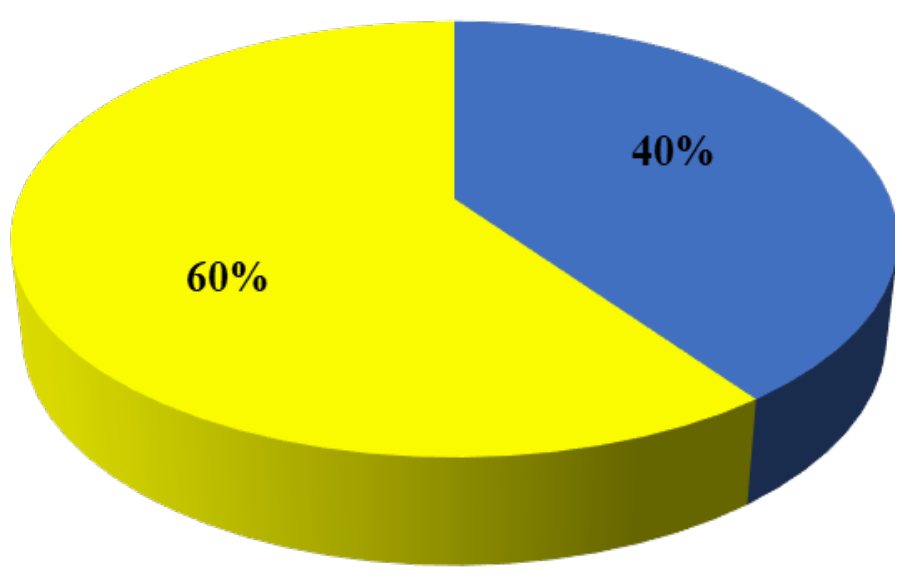

Figura 6. Existência de impermeabilização. 


\section{FOI REALIZADO MANUTENÇÃO (PREVENTIVA/CORRETIVA)}

ロ Sim $\square$ Não

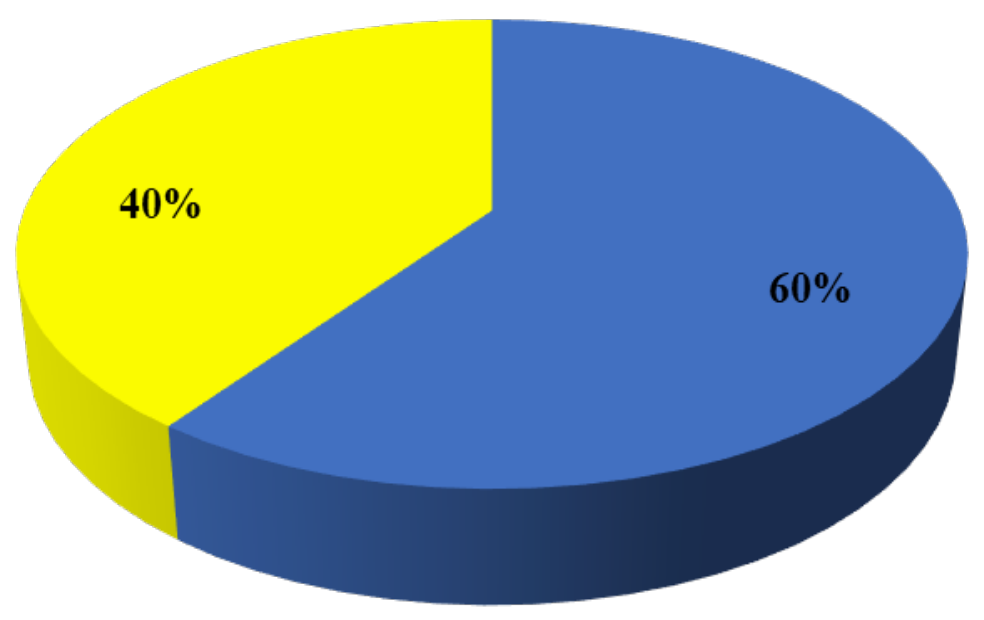

Figura 7. Realização de manutenção nas estruturas investigadas.

A falta de manutenção preventiva ou corretiva apresentado na Figura 7., chega $60 \%$ nas marquises, este resultado mostra que a falta de manutenção corrobora para o surgimento de patologias durante a sua vida útil das peças estruturais investigadas. As estruturas que receberam manutenção (40\%) apresentaram patologias com nível de gravidade baixo. Os valores apresentados na Figura 8 mostram a falta de conhecimento dos proprietários/moradores pela necessidade de manutenção preventiva ou corretiva. 


\section{IMPORTÂNCIA DE MANUTENÇÃO \\ (PREVENTIVA/CORRETIVA)}

\section{- Desconhece $\square$ Conhece}

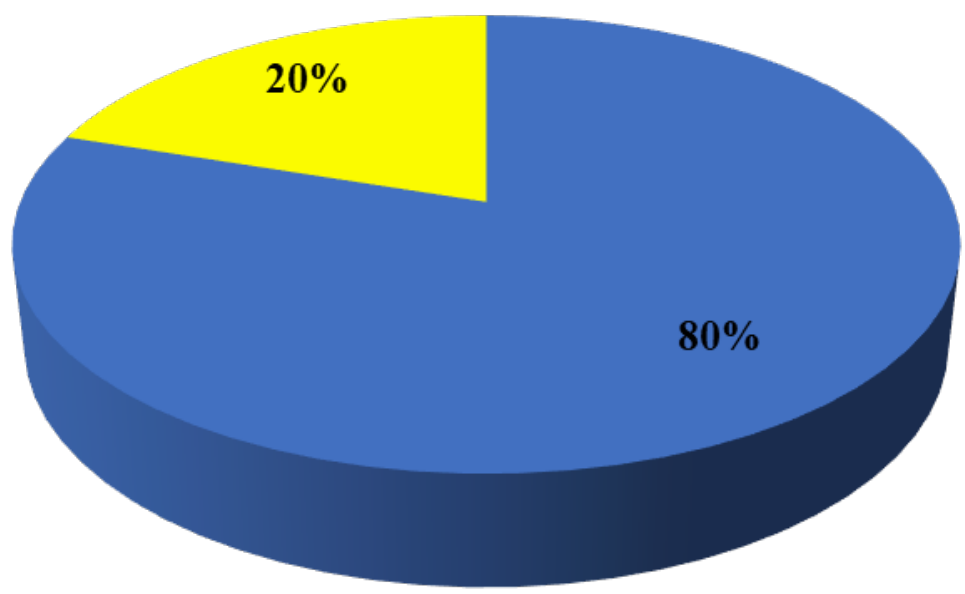

Figura 8. Importância de manutenção, grau de conhecimento do proprietário/morador das marquises investigadas que responderam ao questionário.

Os resultados apresentados na Figura 8., mostram (80\%) dos proprietários/moradores não tem conhecimento da importância das manutenções preventivas e corretivas que deveriam ser executadas nas peças estruturais. Este resultado pode ser consequência da finalidade final do imóvel, onde $( \pm 80 \%)$ são destinados a locação pelos seus proprietários. Este resultado foi coletado de maneira informal durante a aplicação do questionário.

\section{CONCLUSÃO}

Os resultados apresentados nesta investigação mostram que a falta de manutenção corretiva ou preventiva pode ter influenciado no surgimento das patologias encontradas nas marquises investigadas. A investigação mostrou que $60 \%$ não sofreram nem um tipo de manutenção. Isso pode ser resultado da falta de conhecimento do proprietário do imóvel, isso porque $80 \%$ desconhecem a necessidade da manutenção neste tipo de peça estrutural.

\section{REFERENCIAS}

ANDRADE, L. LEVANTAMENTO DE PATOLOGIA CAUSADA POR UMIDADE EM UMA EDIFICAÇÃO NA CIDADE DE PALMAS - TO, Anais do Congresso Brasileiro de Patologia das Construções CBPAT 2016. Belém Pará: 2006. 
ASSOCIAÇÃO BRASILEIRA DE NORMAS TÉCNICAS - ABNT. NBR 6118: Projeto de estruturas de concreto - Procedimento. Rio de Janeiro, 2014.

CARVALHO, E. D. A.; OLIVEIRA, M.; MONTEIRO, E. Análise da Frequência em que Fontes Geradoras de Infiltração Ocorrem em Edifícios Inspecionados na Cidade de Aracaju-SE e Suas Manifestações Patológicas. Revista de Engenharia e Pesquisa Aplicada, v. 6, n. 1, p. 93-100, 19 jan. 2021. http://revistas.poli.br/index.php/repa/article/view/1462

FABIANE SARTORI, K. Levantamento De Manifestações Patológicas Em Marquises De Concreto Armado Survey of Pathological Manifestations in Reinforced Concrete Marquees. Revista Thêma et Scientia -, v. 3, n. 1, p. 69-78, 2013. http://www.themaetscientia.fag.edu.br/index.php/RTES/article/view/125

GASPARETT, A.; PANTOJA, J. DA C.; RAMIRES, F. B. METODOLOGIA PARA INSPEÇÃO E AVALIAÇÃO DA SEGURANÇA E DURABILIDADE DE ESTRUTURAS DE CONCRETO ARMADO / METHODOLOGY FOR INSPECTION AND EVALUATION OF THE SAFETY AND DURABILITY OF REINFORCED CONCRETE STRUCTURES. Brazilian Journal of Development, v. 7, n. 1, p. 4942-4960, 2021.

LORRAN, T. Reformas de casas sobem 57\% na pandemia, diz aplicativo de serviços. Disponível em: $<$ Reformas de casas sobem 57\%25 na pandemia, diz aplicativo de serviços $>$. Acesso em: 6 maio. 2021.

NOVAES, R. F. P. et al. STRUCTURAL RELIABILITY ANALYSIS OF A MARQUEE ELEMENT/ANÁLISE DE FIABILIDADE ESTRUTURAL DE UM ELEMENTO DE MARQUISE. Brazilian Journal of Development, v. 7, n. 2, p. 11928-11941, 2021. https://www.brazilianjournals.com/index.php/BRJD/article/view/24106/19299

OLIVEIRA, M. N. et al. Production of Interlocked block with added Tire Rubber Waste. International Journal of Advanced Engineering Research and Science, v. 8, n. 5, p. 113-116, 2021. https://dx.doi.org/10.22161/ijaers.85.11.

PEREIRA, A. P. et al. Production of Non-Structural Concrete with Addition of Polyethylene Terephthalate Fiber (PET) in Porto Nacional - TO. International Journal of Advanced Engineering Research and Science, v. 6, n. 11, p. 372-378, 2019. https://dx.doi.org/10.22161/ijaers.67

PORTO, T. B.; PIMENTA, G. F. Pathological manifestation analysis in Curvelo-MG building. International Journal of Geoscience, Engineering and Technology, v. 3, n. 1, p. 41-46, 2021.

SEBRAE. Comércio e serviços: Serviços de reparos residenciais. Serviço de ed. Salvador: 2018.

SILVA FERNANDES, F. A. DA et al. Glass foams produced from soda-lime glass waste and rice husk ash applied as partial substitutes for concrete aggregates. Process Safety and Environmental Protection, v. 128, p. 77-84, ago. 2019. https://doi.org/10.1016/j.psep.2019.05.044

SILVESTRO, L.; ROMANO, F. S.; MOLIN, D. C. C. D. Penetração de cloretos em concretos expostos em zona de atmosfera marinha por um período de 9 anos. Ambiente Construído, v. 21, n. 1, p. 101-118, jan. 2021.

WEIMER, B. F. Patologia das estruturas [recurso eletrônico] / Bianca Funk Weimer, Mauricio Thomas, Fernanda Dresch; revisão técnica : André Luís Abitante. Porto Alegre: 2018. 